\title{
基于 SPI 指数的贵州省气象干旱时空演变分析
}

\section{Analysis of Temporal and Spatial Evolution of Meteorological Drought in Guizhou Province Based on SPI Index}

\author{
袁伟蹈 \\ Weitao Yuan \\ 贵州省第一测绘院 贵州 贵阳 550025
}

Guizhou first Institute of Surveying and mapping Guiyang Guizhou 550025

\begin{abstract}
摘 要: 本文以标准化降水指数为气象干旱指标,利用 1960-2016 年逐日的降水数据对贵州省的干旱强度和干旱频率进行特 征分析。研究发现: 1960-2016 年以来贵州省干旱发生频率整体呈下降趋势, 且各地分布不平衡。贵州省以春夏两季干旱较为 严重,秋季次之, 冬季最弱; 气象干旱强度空间分布特征与降雨空间分布特征具有一致性, 呈“北多南少,西多东少”。
\end{abstract}

\begin{abstract}
In this paper, the standardized precipitation index is used as the meteorological drought indicator, and the daily precipitation data from 1960 to 2016 are used to analyze the characteristics of drought intensity and drought frequency in Guizhou Province. The study found that since 1960-2016, the frequency of droughts in Guizhou Province has shown a downward trend as a whole, and the distribution has been uneven across regions. In Guizhou Province, the drought is more serious in spring and summer, followed by autumn, and the weakest in winter. The spatial distribution of meteorological drought intensity is consistent with the spatial distribution of rainfall, showing "more in the north, more in the south, and less in the east".
\end{abstract}

关键词: 气象千旱; 时空分布特征;标准降水指数 (SPI); 贵州省

Keywords : Meteorological drought; Temporal and spatial distribution characteristics; Standard Precipitation Index (SPI); Guizhou Province

DOI : $10.36012 /$ etr.v2i12.3059

\section{1.引言}

旱灾作为影响最为广泛和造成损失最为严重的自然灾 害之一, 干旱主要可以分为 4 种类型[1], 即气象干旱、水文干 旱、农业干旱、社会经济干旱。旱灾不仅可以导致粮食产量和 供水减少、生态环境严重恶化,极端和特重干旱甚至还可以 引起大量人口死亡和朝代更迭, 是制约农业发展、生态环境 保护等的重要影响因素 ${ }^{[2]}$ 。因此根据特定区域选择较客观和 可行的干旱指标进行分析, 不仅可以了解干旱发生、发展的 规律, 预防旱灾; 而且有助于进行旱灾风险评估,防患于未然 [3]。本文利用标准降水指数 (SPI) 可以详细描述干旱发生的起 始、结束时间及干旱的发生过程的优势, 同时结合统计分析
和 ArcGIS 优势性空间分析功能, 研究贵州省长时间序列的 气象干旱强度及频率的时空特征及规律, 为贵州省气象干旱 的监测和预防提供一定的理论依据。

\section{2.研究区概况}

贵州省, 简称 “黔”或“贵”,介于东经 $103^{\circ} 36^{\prime} \sim 109^{\circ} 35^{\prime}$ 、 北纬 $24^{\circ} 37^{\prime}-29^{\circ} 13^{\prime}$ 之间, (如图 1)。由于各种因素的影响, 形 成四季分明, 冬暖夏凉, 雨水丰沛, 光、热、水变化基本同步, 气候地域差异大等气候特点 ${ }^{[4]}$ 。由于每年季风不稳定, 致使 春、夏季雨水年际之间波动和年内雨量时空分布不均而导致 春旱和夏旱, 是贵州农业发展限制的两大气象灾害, 贵州夏 旱的地域分布是东部重、西部轻,或东北部重、西北部轻。 


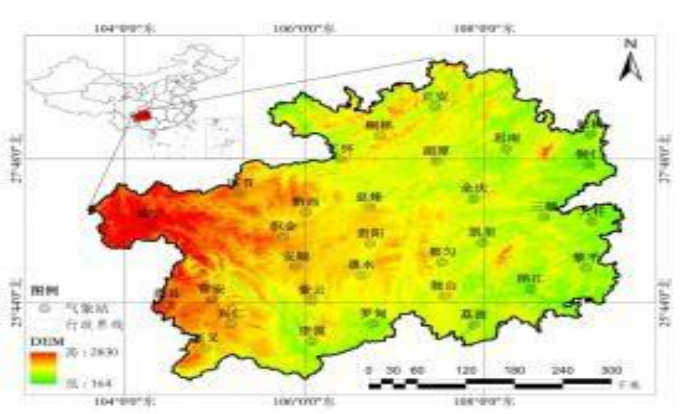

图 1 贵州省气象站点分布图

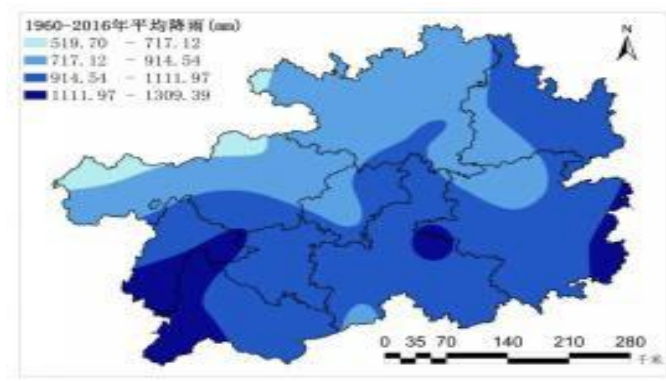

图 2 1960-2016 年平均降雨量分布图

\section{3.数据与方法}

本文研究采用的数据来源于中国气象科学数据服务网 (http://data.cma.cn/)1960-2016 年贵州省 31 个气象站(如图 1 )逐日降水量实测数据。

标准化降水指数 ${ }^{[5]}$ (Standardized Precipitation Index,SPI) 是反映某时段内的降水量出现概率多少的指标之一, 只需要 较长时间的降水量数据, 即可计算不同时间尺度的干旱指 数。利用较长时间的降水量资料,SPI 计算公式如下:

$$
\mathrm{SPI}=\mathrm{s} \frac{\mathrm{t}-\left(\mathrm{c}_{2} \mathrm{t}+\mathrm{c}_{1}\right)+\mathrm{c}_{0}}{\left(\left(\mathrm{~d}_{3} \mathrm{t}+\mathrm{d}_{2}\right) \mathrm{t}+\mathrm{d}_{1}\right) \mathrm{t}+1.0}
$$

公式中:S一概率分布正负系数; $\mathrm{c}_{0} 、 \mathrm{c}_{1} 、 \mathrm{c}_{2} 、 \mathrm{~d}_{1} 、 \mathrm{~d}_{2} 、 \mathrm{~d}_{3} 、-\Gamma$ 分布函数转变为累积频率简化近似求解公式的计算

参数 $\mathrm{c}_{0}=2.515517, \mathrm{c}_{1}=0.802853, \mathrm{c}_{2}=0.010328, \mathrm{~d}_{1}=$ $1.432788, \mathrm{~d}_{2}=0.189269, \mathrm{~d}_{3}=0.001308$ 。

本文研究中计算了 SPI 、SPI3、SPI12 和 SPI36(分别为 1 、 $3 、 12$ 和 36 个月尺度的 SPI 值), 依据相关研究, 对 SPI 进行
干旱等级划分 ${ }^{[6]}$ (表 1)。

表 1 标准降水指数 (SPI) 干旱等级划分

\begin{tabular}{ccc}
\hline 干旱等级 & 类型 & SPI \\
1 & 无旱 & $-0.5<\mathrm{SPI}$ \\
2 & 轻旱 & $-1.0<\mathrm{SPI} \leqslant-0.5$ \\
3 & 中旱 & $-1.5<\mathrm{SPI} \leqslant-1.0$ \\
4 & 重旱 & $-2.0<\mathrm{SPI} \leqslant-1.5$ \\
5 & 特旱 & $\mathrm{SPI} \leqslant-2.0$ \\
\hline
\end{tabular}

\section{4. 结果与分析}

\section{1 干旱强度多尺度分析}

以贵州省 31 个气象站点 57 年逐日降水数据为基础, 分 别计算 1 个月, 3 个月, 12 个月, 36 个月四个时间尺度的 SPI 值(分别用 SPI1、SPI3、SPI12、SPI36 表示), 用以分析贵州省 干旱情况的时间变化特征, 如图 3。随着所选尺度的变大, SPI 浮动的范围减小, 变化区域平稳。较小尺度可以很好的 反映具体的变化特征, 对其变化的响应较显著,正负变化大, 频率变化快; 而较大尺度能从整体上把握大体走势变化问题 [7]。本文主要选用 3 个月时间尺度 (反映季节干旱) 和 12 个 月 ( 反映旱涝阶段性) 时间尺度的 SPI 指数来研究分析, 1 个 月和 36 个月时间尺度的 SPI 指数为对比研究数据。由图 3 (SPI1 值) 可知, 1963 年 1 月 $(\mathrm{SPI}=-2.19) 、 1972$ 年 1 月 $(\mathrm{SPI}=-2.07) 、 1988$ 年 11 月 $(\mathrm{SPI}=-2.25) 、 2010$ 年 2 月 $(\mathrm{SPI}=-$ $2.05)$ 和 2013 年 7 月 ( SPI=-2.28)SPI1 值均小于等于-2.0, 早 情达到特早程度, 而 1969 年 2 月 (SPI=-1.86)、1979 年 11 月 $(\mathrm{SPI}=-1.55) 、 1990$ 年 8 月 $(\mathrm{SPI}=-1.59) 、 1992$ 年 8 月 $(\mathrm{SPI}=-$ $1.67) 、 2001$ 年 9 月 $(\mathrm{SPI}=-1.58) 、 2004$ 年 10 月 $(\mathrm{SPI}=-1.55)$ 、 2007 年 11 月(SPI=-1.97)、2010 年 1 月 (SPI=-1.57)、2011 年 4 月 $(\mathrm{SPI}=-1.53) 、 2011$ 年 7 月 $(\mathrm{SPI}=-1.84)$ 旱情达到严重 干旱程度, 由此可知, SPI1 能很好地反映月尺度特征和干旱 严重程度。 


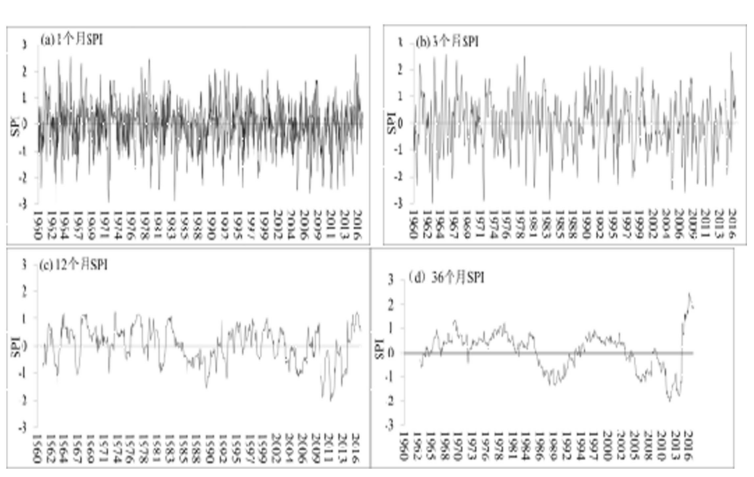

图 3 各时间尺度 SPI 指数时间变化图

由图 3(SPI3 值)看出, 1972 年夏季 $(S P I=-2.05) 、 2010$ 年 春季 $(\mathrm{SPI}=-2.08) 、 2011$ 年秋季 $(\mathrm{SPI}=-2.31)$, 旱情达到特旱; 而 1967 年冬季 $(\mathrm{SPI}=-1.55) 、 1987$ 年春季 $(\mathrm{SPI}=-1.52), 1988$ 年冬季 $(\mathrm{SPI}=-1.51) 、 1989$ 年冬季 $(\mathrm{SPI}=-1.99), 1992$ 年秋季 $(\mathrm{SPI}=-1.68) 、 2007$ 年冬季 $(\mathrm{SPI}=-1.72) 、 2009$ 年秋季 $(\mathrm{SPI}=-$ $1.67) 、 2010$ 年冬季 $(\mathrm{SPI}=-1.67)$ 以及 2011 年春季 $(\mathrm{SPI}=-$ 1.92 ), 旱情达到重旱。由此, 可得 SPI3 能很好地反映气象干 旱情况及研究区季节变化特征。SPI12 和 SPI36 属于较长时 间尺度干旱变化, 旱涝趋势变化特征明显[8], 从图 3(SPI12 值)中可看出 1989 年 9 月至 1989 年 10 月、2010 年 4 月至 2010 年 5 月、2011 年 8 月至 2012 年 4 月处于严重干旱; 从 图 3(SPI36) 中还可以看出, 2011 年 8 月-2012 年 8 月、2013 年 7 月-2014 年 3 月处于重旱的状态, 1990 年 8 月-1991 年 9 月、2005 年 10 月-2008 年 6 月、2012 年 10 月-2013 年 8 月达到中旱。

为更好地描述气象干旱的空间垂直分布特征, 选取 $1960-1970$ 年、1970-1980 年、1980-1990 年、1990-2000 年及 2000-2010 年 5 个时间段点作为研究不同时间尺度的 SPI 指 数的空间分布特征。由图 4 可得: (1)同一年代,不同时间尺 度的 SPI 值对同一地区干旱强度的刻画表现为, 随 SPI 值的 时间尺度的增加, 干旱强度的空间刻画精度降低, 即不同干 旱等级在同一地区的分布级数减少。(2)不同年代, 同一时 间尺度的 SPI 值对贵州省的干旱程度的空间分布特征的表 达, 随时间的不断发展贵州省干旱强度变化特征为贵州省东 北部地区 (遵义及铜仁地区) 干旱强度减弱, 西部地区干旱加 重(毕节及六盘水地区)。

贵州省干旱强度特征表现为: 特旱重旱东北多, 西南少; 随着时间的发展西南地区干旱强度增大, 东北地区干旱强度
逐渐减少(图 4.1970_SPI_1_3-2010_SPI_1_3)。贵州省长时 间序列的年平均降雨量呈现出北少南多的分布特征(图 2)。

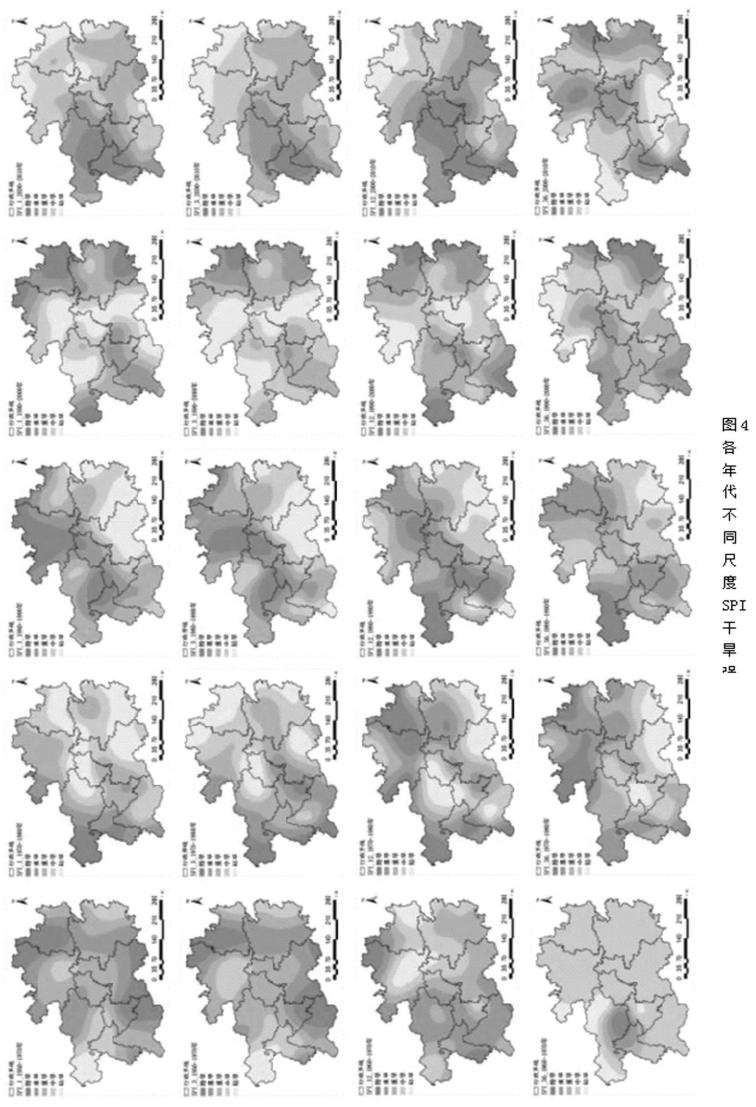

\section{2 干旱频率多尺度分析}

本文为研究贵州省长时间尺度的不同等旱强度干旱频 率的空间分布, 统计 1960-2016 年贵州省不同干旱强度的干 旱的次数, 从而制作 1960-2016 年 SPI 指数不同等级干旱频 率空间分布图(图 5)。总体而言贵州省气象干旱频率分布 呈现出“东多西少, 北多南少”的空间分布规律。

由图 5(a.1960-2016 年轻旱)可得: 贵州省大部分地区 轻旱发生频率介于 $13.36 \%$ 15.46\%, 轻旱高频发生区主要集 中在贵州省的毕节、遵义的西北地区及黔东南地区的东南 部, 干旱发生频率高达 17.19\% 20.18\%。由图 5(b.19602016 年中旱)可得, 贵州省大部分地区中旱发生频率介于 $7.32 \%$ 9.67\%, 中旱高频发生区主要集中在贵州省西部地区 (毕节和六盘水的西部为主)发生频率介于 $10.85 \%$ 12.02\%, 由图 5(b.1960-2016 年重早)可知, 贵州省大部分地区发生 重旱的频率介于 $2.67 \%$ 4.50\%, 重旱高频主要发生在贵州省 毕节大部分地区、贵阳市中南部地区, 且干旱发生频率介于 4.50\% 5.71\%。同理, 由图 5(d.1960-2016 年中早)可得: 全 
省特旱发生频率低于 $10 \%$ 特旱高频发生区位于黔西南南部, 黔南中南部, 铜仁大部分地区及黔东南地区的西北部, 且发 生频率介于 $2.07 \%$ $4.09 \%$ 。

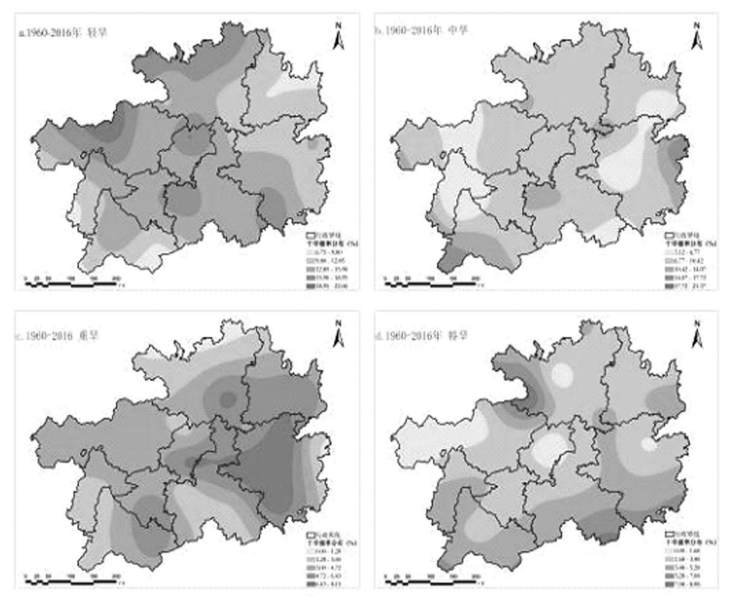

图 5 1960-2016 年 SPI 指数不同等级干旱频率空间分布

本文为更加详细研究贵州省干旱的频率空间分布特征, 以 10 周年为时间尺度, 分别研究贵州省多尺度的干旱频率 空间分布特征(图 6)。依据相关研究理论研究将频率分为 以下 5 类: 低频( $0-20 \%$ )、中低频(20-40\%)、中频( $40 \%$ 60\%)、中高频(60-80\%)、高频(80\%-100\%)。

由较短时间尺度 (SPI1 和 SPI3) 分析可得: 贵州省气象干 旱发生以中低频为主, 且干旱频率呈递减趋势。由图 6 (SPI_1-1960-2010 年) 可得, 贵州省全是干旱的发生以中低 频为主, 低频发生区位于黔西南地区的西南部, 气象干旱低 频发生的原因可能与当地的植被及河流有关系, 中频发生区 位于遵义和安顺的小部分地区, 如图 6(SPI_1_1980-1990 年、SPI_1_2000-2010 年)。由图 6(SPI_3_1960-2010 年)可 得贵州省干旱发生频率整体由中低频转变为低频, 除 19801990 年间, 遵义大部分地区及贵阳市东南大部分地区、黔南 西北少部分地区是干旱中频发生区如图 6(SPI_3_1980-1990 年)。

由长时间尺度 (SPI12 和 SPI36) 分析可得: 贵州省气象干 旱发生频率总体呈显著增加趋势, 以 1980-1990 年间最为显 著, 频率分布呈“东高西低, 北高南低”分布。由图 6.SPI12 得:气象干旱发生以低频和中低频为主(SPI_12_1960-1980 年), 中低频发生区主要分布于贵州省西南大部分地区、毕节 东北部、遵义西部及东北地区(SPI_12_1960-1970 年); 中频 发生区主要集中在铜仁及贵阳整体地区、遵义东部、黔东南
大部分地区及毕节西部地区 (SPI_12_1980-1990 年);贵阳、 毕节地区、安顺地区、六盘水地区、黔南地区的大部分地区、 遵义西部、铜仁东南部、黔西南地区西南部及黔东南地区中 部小部分地区(SPI_12_2000-2010 年); 中高频发生区位于毕 节西北部和黔南地区的中部及西南小部分地区

(SPI_12_2000-2010 年)。

总体来看贵州省气象干旱主要以轻旱和中旱为主, 全省 干旱频率以低频和中低频为主, 频率分布呈现出“东少西多, 南少北多”的特征, 中频发生区在 1980-1990 年主要分布于 贵州省的东部地区, 在 2000-2010 年分布以贵州省西部为 主, 中高频和高频发生区很少且面积很小。

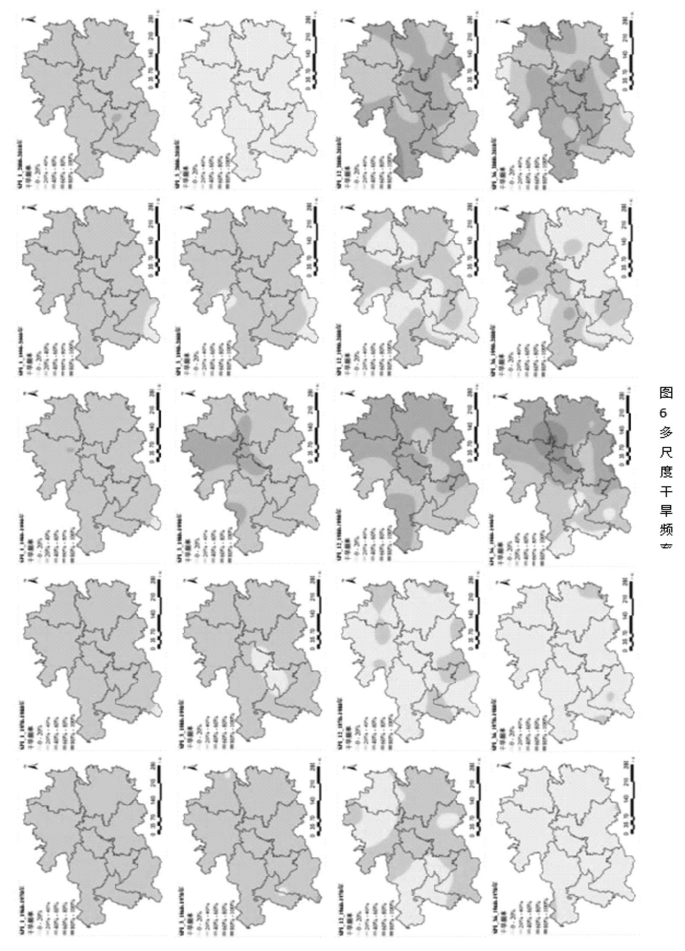

\section{5.结论}

本文基于 1960-2016 年实测气象数据, 利用 SPI 定量分 析了贵州省不同时间尺度干旱发生频率和发生强度, 揭示了 贵州省干旱发生的时空演变特征及趋势特征。主要结论包 括:

(1)近 53 年贵州省不同时间尺度 SPI 对降水量变化的 敏感程度不同, 同一时间尺度的 SPI 值对贵州省的干旱程度 的空间分布特征表现为随时间的发展贵州省整体干旱区面 积逐渐减少, 特旱及重旱地区面积尤为显著, 以及干旱的空 间分布特征为随时间的变化干旱发生区域由贵州省东北部 
地区逐渐向西南地区移动。

(2)贵州省季节性干旱强度特征为随时间变化夏旱的干 旱强度逐渐降低, 其他季节干旱强度有所增加。

(3)从时空特征分析可得, 贵州省气象干旱发生分布呈 “北多南少, 西多东少”空间特征, 且与降雨空间分布特征具 有一致性。对于季节性干旱, 贵州省春夏两季干旱较为严 重, 秋季次之, 冬季最弱。贵州省气象干旱强度及频率总体 呈下降趋势。

\section{参考文献}

[1] 郑秋红, 杨霏云, 罗蒋梅. 3 种常用农业气象干旱指标及其在实际 应用中的修订[J].中国农学通报,2015,31(09):252-256.

[2] 夏敏,孙鹏,张强等. 基于 SPEI 指数的淮河流域干旱时空演变特 征及影响研究[J].生态学报,2019,39(10):3643-3654.
[3] 王旖㻈, 杜鹃, 徐伟.辽宁省农业气象干旱灾情时空特征分析[J]. 国土与自然资源研究,2019(02):85-91.

[4] 程清平. 基于网格的贵州省干旱时空变化特征与旱灾风险评估 [D].福建师范大学, 2017 .

[5] 袁文平,周广胜.标准化降水指标与 $\mathrm{Z}$ 指数在我国应用的对比分 析[J].植物生态学报,2004,28(4):523-529.

[6] 张强,邹旭恺,肖风劲,等.气象干旱等级 (GB/T20481-2006)[S]. 北京:中国标准出版社,2006:12-17.

[7] 李韵婕.中国西南地区区域性气象干旱事件的特征及成因诊断 [D].南京信息工程大学,2014.

[8] 严小冬,李扬,夏阳,胡跃文,杨春艳.1961-2016 年贵州省持续 性干旱特征及成因分析[J].中低纬山地气象,2019,43(03):1-7.

\section{(上接第 29 页)}

至 $0.6 \mathrm{Mpa}$ 稳压 1 小时,并再次检查各户室内是否漏水, 压力 降不超过 $0.05 \mathrm{MPa}$ 则试压合格。

(4)试压完毕放水, 从一楼注水处放水到室内下水管道 中, 再将地下室中存水通过泄水阀门放水, 用污水洜将地沟 中的水排至室外污水管网, 再将泄水阀门关闭。

\section{2 对室外采暖、热水管网进行试水、试压。}

(1)将出交换站的各系统供回水总阀门关闭(或加装盲 板), 再将各栋楼的人单元供回水总阀门关闭(或加装盲板), 关闭不严的戈门进行清理或者更换新阀门。

(2) 对室外管网逐根管道分别注水,并沿管道敷设位置 检查是否有漏水现象 (必要时, 可采用检漏仪), 若发现地埋 管道漏水, 将漏水部位挖出并进行处理, 处理完毕后, 再进行 注水,管道在 $0.4 \mathrm{MPa}$ (自来水压力下) 保持 24 小时,管网无 渗漏; 再用打压泵升压至试验压力 (1.0Mpa), 稳压 10 分钟, 压力降不超过 $0.05 \mathrm{Mpa}$ 为合格。

(3)试压合格后, 地埋漏水部位管道回复原有的刷漆保 温, 地埋的覆土恢复原状。打开交换站的各系统供、回水总划 门(去除盲板)和每个系统末端入单元供、回水总划门(去除
盲板), 从交换站内进行注水, 并启动循环水泵, 进行室外管 网冲洗, 将管网中的杂质冲洗干净, 以水色不混浊为合格。

随后于 12 月 30 日 1 月 2 日组织了三个小区采暖系统 的冷态试运行和管网冲洗工作, 期间小区各住户积极配合, 保证了小区冷态试运安全, 达到给住户造成损失最小。并于 2017 年 1 月 15 日市政开始缓慢供热, 保证了三个小区供热 时,未出现大的问题,项目部并安排各试水试压承包单位留 有值班维修人员及联系方式, 保证电话 24 小时畅通, 针对出 现问题能够及时处理。

\section{5. 结束语}

经过三个月紧张的按部就班程序试水试压工作, 解决了 室内外管道系统存在等 $95 \%$ 以上的问题, 某小区三个小区供 暖、热水系统水压试验和维修工作圆满结束。市政热网热水 送达某小区各交换站, 小区采暖系统运行正常, 达到了预期 的效果。

\section{参考文献}

[1] 李安桂,史丙金,张婉卿, 李成, 毛晶晶.基于太阳能利用的相变蓄 热水箱结构优化[J].太阳能学报.2020(02) 